\title{
Tradisi Adat Mappadendang Pationgi Patimpeng 1983- 2016
}

\author{
Gustiana $^{1}$, Najamuddin ${ }^{2}$, Jumadi $^{3}$ \\ ${ }^{1}$ Pendidikan Sejarah Fakultas Ilmu Sosial Universitas Negeri Makassar, Indonesia \\ Email: gustiana.history4@gmail.com
}

\begin{abstract}
Abstrak
Penelitian ini bersifat deskriptif historis dengan menggunakan metode penelitian sejarah,melalui tahapan-tahapan kerja yang meliputi; heuristik, kritik, interpretasi, dan historiografi. Heuristik adalah tahap pengumpulan sumber- sumber sejarah, sumber tersebut kemudian dikritik untuk mendapatkan fakta dengan fakta lainnya. Sebagai tahap terakhir adalah historiografi atau penyajian, yaitu merekontruksi peristiwa-peristiwa sejarah menjadi kisah sejarah dalam bentuk deskriptif historis. Hasil penelitian tersebut menunjukkan bahwa proses ritual adat Mappadendang (pesta panen adat bugis) yang ada di Kabupaten Bone sangat terstruktur dan tersusun secara rapi. Diawali dari penentuan hari pelaksanaan dan durasi atau lama waktu pelaksanaanya. Setelah proses penentuan waktu selesai, maka keluarga yang akan melaksanakan pesta adat tersebut mulai menyusun susunan acara pesta adat Mappadendang. Seperti, acara hiburan dan pemain yang akan menjadi penumbuk alu pada lesung serta atribut yang digunakan pemain pada pesta adat tersebut. Pesta adat tesebut berakhir dengan ditandai makan bersam oleh seluruh masyarakat yang hadir dalam pesta adat tersebut. Dalam pesta adat Mappadendang terdapat makna, nilai- nilai serta fungsi yang terkandung di dalamnya, makna tersebut diaplikasikan dalam bentuk perbuatan seperti rasa syukur terhadap tuhan yang dan menghargai serta menjaga warisan leluhur atau nenek moyang. Begitupun dengan nilai- nilai yang terkandung dalam pesta adat Mappadendang, nilai- nilai kebersamaan, kekeluargaan, hiburan dan religi melebur menjadi satu dalam sebuah pesta adat yang terus dilestarikan dan menjadi pedoman hidup masyarakat.
\end{abstract}

Kata Kunci : Tradisi, Mappadendang dan Patimpeng

\begin{abstract}
This research is historical descriptive by using historical research methods, through work stages which include; heuristics, criticism, interpretation, and historiography. Heuristics is the stage of gathering historical resources, the source is then criticized for obtaining facts with other facts. As the last step is historiography or presentation, which is reconstructing historical events into historical stories in historical descriptive form. The results of the study show that the traditional ritual process of Mappadendang (Bugis traditional harvest party) in Bone Regency is very structured and neatly arranged. Starting from the determination of the day of implementation and the duration or duration of implementation. After the process of determining the time is complete, the family who will carry out the traditional feast begins to arrange the order of Mappadendang traditional parties. Like, entertainment programs and players who will become pestle pounders on mortar and the attributes used by players at the traditional party. The traditional party ended with a marked meal by all the people who attended the traditional party. In the Mappadendang traditional party there are meanings, values and functions contained in it, the meaning is applied in the form of actions such as gratitude to God who and respect and safeguard ancestral or ancestral heritage. Likewise with the values contained in the Mappadendang traditional party, the values of togetherness, family, entertainment and religion merge into one in a traditional feast that continues to be preserved and becomes a guideline for people's lives.
\end{abstract}

Keywords: Tradition, Mappadendang and Patimpeng 


\section{A. Pendahuluan}

Berbicara mengenai Tradisi, hubungan antara masa lalu dan masa kini haruslah lebih dekat.Tradisi mencakup kelangsungan masa lalu dimasa kini ketimbang menunjukkan fakta bahwa masa kini berasal dari masa lalu, kelangsungan dimasa kini mempunyai dua bentuk material dan gagasan atau objektif dan subjektif.

Proses perwarisan Kebudayaan terlaksana dalam waktu yang sangat lama, generasi dan mengalami perubahanperubahan ada yang punah ada yang menjelma dalam bentuk lain,ini merupakan perubahan kebudayaan dan perkembangan kebudayaan. (Nonci, 2006)

Tradisi dalam bahasa latin yang berarti diteruskan atau kebiasaan dalam pengertian yang paling sederhana ialah sesuatu yang telah sejak lama dan menjadi bagian dari kehidupan suatu kelompok masyarakat. Menurut Piort Sztompa bahwa Tradisi adalah keseluruhan benda material dan gagasan yang berasal dari masa lalu namun benar-benar masih ada kini,belum dihancurkan, dirusak, dibuang, atau dilupakan. (Sztompa, 2008) Sejalan dengan itu , menurut kamus besar bahasa Indonesia,Tradisi adalah alat atau kebiasaan turun-menurun (nenek moyang) yang masih dijalankan dimasyarakat. Penilaian atau anggapan bahwa cara-cara yang telah ada merupakan yang paling baik dan benar. Wujud budaya yang paling menonjol adalah pemukiman dalam arti tempat tinggal penduduk dan tempat penduduk melakukan semua aktivitas baik yang bersifat material dan spiritual.sebagai wujud nyata dan lingkungan budaya, pemungkiman dan perkotaan sangat berbeda disbanding dengan pemukiman masyarakat pedesaaan.

Tradisi merupakan akar dari kebudayaan yang biasa menjadi sebuah kondisi yang aman dan nyaman bagi masyarakatnya untuk melalkukan berbagai kegiatan dalam kehidupan sehari-sehari, hal tersebut dapat kita temui bahwa tradisi merupakan unsur penting dalam kehidupan manusia meskipun peradaban dan berbagai kondisi kehidupan telah berubah namun hal tersebut tidak akan dengan cepat mengubah kebiasaan atau tradisi asalnya.

Kata "Kebudayaan" berasal dari bahasa sansekerta buddhyiah, yaitu bentuk jamak dari buddi berarti "budi atau akal". Dengan demikian kebudayaan dapat diartikan : "hal-hal yang bersangkutan dengan akal. Menurut E. B.Tylor seorang ahli antropologi dalam buku berjudul "primitive culture", kebudayaan adalah keseluruhan kompleks yang didalamnya terkandung ilmu pengetahuan yang lain,serta kebiasaan yang didapat manusia sebagai anggota masyarakat.

\section{B. Metode Penelitian}

Dalam melakukan suatu penelitian, banyak cara yang dilakukan oleh para peneliti baik berdasarkan proses, prosedur, maupun prinsip yang dianut. Dengan demikian, berdasarkan atas tujuan dan kategori data yang dibutuhkan, menyebabkan terjadinya perbedaan metode yang diterapkan dalam kegiatan penelitian. Beberapa metode yang umum digunakan dalam penelitian, salah satunya yaitu penelitian sejarah. (Ahmadin., 2013)

Metode sejarah merupakan cara atau teknik dalam merekonstruksi peristiwa masa lampau, melalui empat tahapan kerja, yaitu heuristic (pengumpulan sumber), kritik sumber (eksternal/ bahan dan internal/isi ), interpretasi (penafsiran), dan histografi (Penulisan kisah sejarah). (Hamid., 2008) Metode sejarah bertujuan memastikan dan mengatakan kembali fakta masa lampau. Terdapat emapat langkah metode sejarah yang wajib hukumnya dilaksanakan oleh sejarawan dalam menulis karya sejarah, Diantaranya :

\section{Heuristik}

Sebelum menentukan teknik pengumpulan sumber sejarah, pertamatama yang perlu di pahami adalah bentuk dari sumber sejarah yang akan dikumpulkan. Penentuan sumber sejarah akan mempengaruhi tempat (dimana) atau siapa (sumber informasi lisan ) dan cara 
memperolehnya . sumber sejarah dibedakan atas sumber tulisan, lisan dan benda. Sumber-sumber itu sendiri ada dua jenis yaitu sumber primer dan sumber sekunder . sumber primer merupakan sumber utama dari topic penelitian, misalnya arsip, dokumen, sumber lisan, dan sumber benda. Adapun sumber sekunder merupakan sumber pelengkap, seperti buku, jurnal, dan laporan hasil penelitian ( skripsi).

\section{Kritik}

Setelah memperoleh sumber-sumber yang cukup memadai, selanjutnya dilakukan kritik (penyaringan) terhadap sumber tersebut. Kritik terhadap sumber bertujuan untuk memperoleh fakta-fakta yang seobyektif mungkin, sehingga karya sejarah yang dihasilkan merupakan produk dari proses ilmiah yang dapat dipertanggung jawabkan, bukan hasil dari suatu fantasi maupun manipulasi. (Sjamsuddin., 2012) Ketika melakukan kritik sumber, dua hal penting yang harus dilakukan, yakni kritik otentisitas (kritik ekstern) dan kritik kredibilitas (kritik intern).

\section{Interpretasi}

Tahapan selanjutnya setelah proses kritik adalah penginterpretasi. Pada tahap interpretasi ini, subyektivitas seorang peneliti aakan mulai tampak. Hal ini dapat dipahami karena pada tahap ini imajinasi dibutuhkan untuk menafsirkan seluruh kejadian berdasarkan fakta-fakta sejarah yang telah di peroleh pada tahapan sebelumnya

\section{Historiografi}

Tahapan yang terakhir adalah historiografi atau penulisan sejarah, pada tahapan ini merupakan puncak dari segalanya dalam metode penelitian sejarah. Historiografi merupakan puncak dari segala dalam metode penelitian sejarah. Sejarawan pada fase ini mencoba menangkap dan memahami historio recite atau sejarah sebagaimana mestinya. (Surjomiharjo, 1985)

\section{Tinjauan Penelitian}

Dalam setiap penyusunan karya ilmiah, tentu dibutuhkan sumber-sumber sebagai pendukung dan penguat data. Oleh sebab itu diperlukan suatu langkah yang disebut telaah pustaka. Hal ini dimaksudkan guna menjelaskan secara umum mengenai beberapa data atau referensi yang berasal dari tulisan orang lain, sehingga akan memperlihatkan perbedaan mendasar objek dan cakupan yang ingin di teliti. Langkah ini menjadi penting,sebab menghindari adanya upaya penciplakan karya orang lain. Peneliti tentang Mappadendang sebelumnya telah ada yang mengkaji yaitu dalam bentuk skripsi tahun 2010 Fakultas Ilmu Sosial ,Universitas Negeri Makassar,yang di tulis oleh nita ryani dengan judul Tradisi Adat Mappadendang dalam masyarakat petani Di Kabupaten Sidenreng Rappang.skripsi ini membahas tentang bagaimana Tradisi Mappadendang diadakan,namun fokus wilayahnya berada di wilayah Sidenreng Rappang, sementara dalam skripsi yang saya buat membahas tentang latar belakang diadakannya tradisi adat Mappadendang , proses pelaksanaan tradisi adat Mappadendang, nialai-nilan dan makna tradisi Mappadendang serta fungsi trdisi adat Mappadendang. (riyani, 2010)

\section{Pembahasan}

\section{Latar belakang di adakannya Tradisi Adat Mappadendang Di Desa Pationgi Kecamatan Patimpeng Kabupaten Bone}

Acara Mappadendang ( pesta panen Adat Bugis) atau lebih dikenal dengan sebutan pesta tani pada suku bugis merupakan suatu pesta syukur atas keberhasilannya dalam menanam padi kepada yang maha kuasa. Mappadendang sendiri sendiri merupakan suatu pesta yang diadakan dalam rangka besarbesaran.yakni acara penumbukan gabah pada lesung dengan tongkat besar sebagai penumbuknya. Acara Mappadendang sendiri juga memiliki nilai magis yang lain. Disebut juga sebagai pensucian gabah dalam artian masih terikat dengan 
batangnya dan terhubung dengan tanah menjadi ase ( beras) yang nantinya akan menyatu dengan manusianya. Olehnya perlu dilakukan pensucian agar lebih berberkah.

Mappadendang merupakan upacara syukuran panen padi dan merupakan adat masyarakat bugis sejak dahulu kala biasanya dilaksanakan setelah panen raya biasanya memasuki musim kemarau. Pada dasarnya Mappadendang berupa bunyi tumbukan alu kelesung yang silih berganti sewaktu menumbuk padi komponen utama dalam acara ini yaitu 6 perempuan, 3 pria, bilik baruga, lesung alu, dan pakaian tradisional yaitu baju bodo.pesta adat ini merupakan pertunjukan unik yang menghasilkan bunyian irama teratur atau nada dari kelihaian pemain,para perempuan yang bertugas dibilik baruga disebut pakkindona sedangkan pria yang menari dan menabur bagian ujung lesung disebut pakkimbona. Bilik baruga terbuat dari bamboo, serta memiliki pagar yang terbuat dari anyaman bambu yang disebut walasoji.

\section{a. Waktu Pelaksanaan Ritual Adat Mappadendang}

Begitupun dengan pesta adat Mappadendang, yang memiliki waktu khusus dalam setiap pelaksanaannya. Pada masyarakat suku bugis waktu pelaksanaan pesta adat Mappadendang juga memiliki waktu khusus dalam pelaksanaanya, namun ada banyak asumsi dalam masyarakat saat ini bahwa pelaksanaan pesta adat Mappadendang bisa dilaksanakan di harihari biasa tanpa memperhatian waktu khusus yang telah ditentukan. Menurut abbas yang merupakan salah satu masyarakat Desa Pationgi dan juga sebagai salah satu pemain dalam pesta adat Mappadendang mengungkapkan bahwa Mappadendang dilaksanakan sekali dalam setahun ketika musim panen dan memasuki musim kemarau. Namun ketika ada kelompok tani dan pemerintah yang ingin melaksanakan, pesta adat Mappadendang bisa dilakukan pada harihari biasa sesuai keputusan pemerintah. "ta'cinami yanni $\mathrm{ku}$ wennimi, $\mathrm{ku}$ pamarenta'e biasa maundangi yaku essowi, untu'anunna kelompo' tani'e aga yanni ku essoi naseng, tapi yatossi ku masyaraka'e rekeng yaro rekeng $k u$ maga sennaro, yaro ku pura panen tau'e wenni pi nappa nalaksanakang yaro mappadendang'e”. (Abbas, 2018)

Terjemahan:

sebentarji biasanya kalau malam hari , biasanya juga acara Mappadendang ini dilaksanakan di siang hari, untuk acaranya kelompok tani karena merupakan undanagan atau panggilan dari pemerintah. Tapi kalau masyarakat memperhitungkan waktunya, memperhitungkan waktunya bagaimana namanya itu, oh kalau masyarakat telah melaksanakan panen, itu acara Mappadendang harus dilaksanakan kalau malam hari”.

Adapun maksud dari penjelasan abbas bahwa pesta adat Mappadendang jika dilaksanakan oleh masyarakat setempat dan untuk mengungkapkan rasa syukur atas keberhasilan panen padi masyarakat maka harus dilaksanakan setelah musim panen dan memasuki musim kemarau dimalam hari, dilaksanakan pada malam hari karena pada saat memasuki musim kemarau akan terjadi bulan purnama, akan tetapi jika pesta adat Mappadendang dilaksanakan oleh kelompok tani dan pemerintah maka pesta adat tersebut dapat dilaksanakan kapan saja meskipun belum memasuki masa panen atau musim kemarau, karena hanya sebatas seremonial dan sebagai usaha pemerintah setempat untuk melestarikan budaya tersebut.

Hal ini juga dipertegas oleh latalibe salah satu warga Desa Pationgi yang sering mengikuti pesta adat Mappadendang bahwa pesta adat Mappadendang harus dilaksanakan cukup satu hari satu malam, dan pesta adat Mappadendang harus dilaksanakan pada malam hari tapi untuk pesta adat yang dilaksanakan oleh 
kelompok tani dan pemerintah dapat dilaksanakan kapan saja.

"biassanna tassiwenni ndi. Mederritokka yolli rekeng ku engkasi kaperluang sibawa acara- acara, yaku engkasi janci- jancinna kulosi mattaneng ase apa' biasanna engka nia'-nia'na tau'e yaku janci asena, apa' yangga to rekeng ade'ta metto riolo sibawa ade' kesenian maloppota. Kalo siang biasanna engka ndi', yaku acara pertaniang yarega acara pamerang, tapi yatosi ku masyaraka,e yapa ku wenni w, napeagau'I appadendang'e. (Latalibe, 2018)

\section{Terjemahan:}

"biasanya itu satu malamji, sering dipanggil ikuti acara, misalnya ada keperluan sama acara- acara, kalau ada juga janji- janji mau tanam padi, karena biasa ada niat- niat orang kalu mau panen padi, nanti sudah panen orang kalua jadi padinya atau sukses panen rayanya, karena dianggap sebagai adat kesenian besar orang bugis”.

Bagi masyarakat Desa Pationgi, pesta adat Mappadendang adalah warisan dari leluhur mereka untuk mengungkapkan rasa syukur atas berkah dan keberhasilan dalam masa panen padi yang mereka laksanakan saekali dalam setahun setelah musim panen dan memasuki musim kemarau. Hal ini senada dengan apa yang diungkapkan oleh pendre bahwa pesta adat Mappadendang adalah adat yang di wariskan nenek moyangnya dan harus dilaksanakan ketika hasil panennya melimpah serta dilaksanakan pada malam hari.

"Eehh anu itu mappadendang ndi" sudah tururn- temurun dari nenek moyangta dulu, eehh kalo baguski hasil panen berarti haruski bikin padendang'e, baru malampi juga kah tidak adami dikerja kalo malam pulang tidak adami orang kerja disawah”.
Dari hasil wawancara dengan pendre dan Nurbaya, dapat dilihat bahwa pesta adat Mappadendang merupakan adat turun- temurun dan warisan dari nenek moyang mereka. Pesta adat Mappadendang dilaksanakan oleh masyarakat setempat sebagai ungkapan rasa syukur kepada tuhan terhadap hasil panen padi yang melimpah, masyarakat setempat melaksanakan pesta adat Mappadendang sekali dalam setahun setelah musim panen padi.

Berdasarkan hasil penelitian telah diketahui bahwa sebenarnya pesta adat Mappadendang merupakan adat warisan turun- temurun dari leluhur masyarakat Desa Pationgi, pesta adat Mappadendang dilaksanakan oleh masyrakat setempat satu kali dalam setahun ketika musim panen padi dan memasuki musim kemarau di malam hari. Pesta adat Mappadendang dilaksanakan selama satu hari atau sampai padi yang akan ditumbuk habis. Ketika memasuki musim kemarau, bulan purnama akan muncul cahaya bulan purnama akan terlihat cukup terang untuk memberikan pencahayaan pada masyarakat yang sedang melaksanakan pesta adat mappadendang. Lain halnya dengan pesta adat mappadendang yang dilakukan kelompok tani dan pemerintah, jika masyarakat setempat melaksanakan pesta adat Mappadendang maka waktu pelaksanaanya harus dimalam hari ketika musim panen dan memasuki musim kemarau. Namun ketika kelompok tani dan pemerintah yang akan melaksanakan pesta adat mappadendang maka hal tersebut akan dilaksanakan kapan saja tanpa mengikuti aturan waktu pelaksanaanya karena kelompok tani dan pemerintah melaksanakan pesta adat mappadendang untuk acara pemerintahan, memperingati hari besar dan sekaligus sebagai usaha pemerintah dalam melestarikan budaya lokal.

Dari apa yang telah di simpulkan oleh beberapa informan tersebut, dapat diketahui bahwa pesta adat Mappadendang merupakan hal yang cukup penting bagi 
kehidupan masyarakat setempat, karena Mappadendang dianggap sebagai metode dan wadah mereka dalam mengaplikasikan rasa syukur mereka kepada tuhan. Hal ini dibuktikan dengan masih maraknya dilaksanakan pesta adat tersebut.

a) Cara Pelaksanaan Ritual Pesta Adat Mappadendang Di Desa Pationgi Kecamatan Patimpeng Kabupaten Bone

Pesta adat ini merupakan bentuk pergelaran seni tradisional bugis karena merupakan bentuk pertunjukan unik yang menghasilkan bunyian irama tertentu atau nada dari kelihaian pemain, pemain ini lebih dikembangkan lagi dimana alunan irama lebih teratur disertai dengan variasi bunyi dan gerakan bahkan disertai dengan tarian padendang Ogi. Gerakan dan bunyi irama dianggap sebagai sebuah ungkapan kebahagiaan dan rasa syukur kepada tuhan yang disampaikan dalam bentuk gerakan dan bunyi irama tersebut.

Bagi masyarakat Desa Pationgi, bertani tidak hanya sekedar mengarap lahan lalu mengambil hasilnya, tetapi juga menjaga tradisi yang telah diwariskan oleh nenek moyang mereka yaitu ungkapan terima kasih kepada tuhan atas berkah dan limpahan rezekinya dalam bertani yang dibingkai dalam sebuah pesta adat Mappadendang. Didalam pelaksanaanya pesta adat Mappadendang memiliki cara pelaksanaanya tersendiri, seperti yang diungkapkan latalibe salah seorang warga desa pationgi yang juga merupakan pemain dalam pesta adat Mappadendang bahwa pesta adat Mappadendang terdiri dari tujuh orang pemain, terdiri dari empat perempuan dan tiga laki- laki tersebut memiliki posisi dan tugasnya masingmasing dalam pesta adat Mappadendang tersebut.

"oh biasanna tappitumi tau ndi, yatega eppa makkunrai tellu burane. Eppa makkunrai'e sebagai indo' padendangna senna yaro, misalna to kang engka palacce'na kuhe yaro tellu burane kure monroh, kang engka seggona palungengnge kuhe monro tettong siolong, engka tona monro ceddi kuhe monro, yenaro monro sipadu- padudung, nappa yaro makkunra'e eppa'e siolong to, dua kuhe dua to kuhe".

Adapun maksud dari pernyataan latalibe yaitu dalam pesta adat Mappadendang setiap pemain memiliki posisi dan tugasnya masing agar pelaksanaan pesta adat tersebut dapat terlaksana dengan baik, keempat pemain perempuan tersebut memiliki sebutan nama yaitu Indo' Padendangdan memiliki posisi berdiri berhadapan disamping kiri dan kanan lesung. Sedangkan , ketiga pemain laki- laki tersebut berdiri saling berhadapan diujung lesung dan yang satunya lagi berdiri diujung depan lesung di sebut Ambo' Padendang . setelah pemain menempati posisinya masing- masing, maka mereka akan menjalankan tugasnya masingmasing dalam pesta adat Mappadendang tersebut yaitu menumbuk padi dengan gerakan dan suara yang berirama. Suara benturan antara kayu penumbuk yang disebut Aludan Palungeng ini biasanya terdengar nyaring . membentuk irama ketukan yang khas bergantian dan teratur. Gerakan dan bunyi tumbukan berirama inilah yang menjadi ciri khas Mappadendang. Hal ini seperti yang diungkapkan oleh latalibe bahwa pemain dalam pesta adat Mappadendang harus bisa menumbuk alu pada palungeng bersamaan dan berirama, akan tetapi ketika pemain pada pesta adat mappadendang merasa lelah maka akan di gantikan oleh pemain lainnya yang telah di siapkan.

“ohh, sisulle- sullema yaku
matekko'I, siselle- selle yaro
buranewe yaro tellu'e tapi yare
eppa'e makkunrai'e de wedding
isullai apa' deweddingngi
massambarangeng tette rekeng kuro
monro mannampu, weddimma je
isullai yaku engka misengngi apa'
pake irama rekeng jaji de
yassembarangeng ipa'cule tau'e.

Volume 6 No.1 Januari-Maret 2019, 43-55 | 48 
Terjemahan :

"ohh antara perempuan dan lakilaki mereka saling berganti, baku ganti- gantiji itu laki- lakinya yang tiga tapi yang itu empat perempuannya tidak bisa di ganti karena tidak biss diganti sembarangan tetap disitu tinggal menumbuk padi, bisaji diganti sebenarnya tapi perempuannya itu harus yang pintar menumbuk padi, karena menggunakan irama jadi tidak bisa sembarang dikasi main orang”.

Dari apa yang diungkapkan Latalibe sangat jelas bahwa dalam pelaksanaan pesta adat Mappadendang memiliki tata cara yang harus diketahui oleh setiap pemain, dalam hal ini setiap warga yang ingin ikut serta dalam pesta adat Mappadendang harus bisa memadukan irama tumbukan Alu dan Palungeng. Dan alat musik lainnya yang digunakan pada saat pesta adat Mappadendang. Dari apa yang diungkapkan oleh narasumber diatas dapat dilihat bahwa salah satu tangan pemain digunakan untuk menggenggam Alu sambil menumbuk dan salah satu tangannya lagi digunakan untuk membolak balikkan padi yang sedang ditumbuk. Secara sederhana dapat dipahami bahwa irama tumbukan Alu pada Palungeng juga berfungsi untuk mencegah cedera pada pemain pada saat melaksanakan adat Mappadendang.

Selain memadukan irama tumbukan $A l u$ dan Palungeng dengan alat musik yang digunakan,pesta adat Mappadendang juga dimeriahkan oleh beberapa pertunjukkan. Pertunjukkan tersebut dirangkai dalam sebuah susunan acara yang dibuat oleh keluarga atau pemerintah yang ingin melaksankan pesta adat Mappadendang. Seperti yang diungkapkan oleh Mashar salah seorang warga Desa Pationgi yang juga rutin mengikuti pesta adat Mappadendang setiap tahunnya. "kalau ada acara Mappadendang mau dilaksanakan biasanya ada yang urus persiapannya bikin susunan acaranya, dan susunan acaranya itu biasanya dimasukkan pembacaan cerita rakyat bugis, menari- menari sampai acara makan- makan." (Mashar, 2018)

Dari apa yang dijelaskan oleh narasumber diatas dapat dilihat bahwa dalam pelaksanaanya pesta adat Mappadendang, keluarga atau pemerintah yang melaksanakan pesta adat Mappadendang menampilkan sebuah pertunjukkan seperti tari- tarian, pembacaan cerita rakyat bugis dalam bentuk nyanyian yang dilanjutkan dengan makan bersama masyarakat yang hadir menyaksikan pesta adat Mappadendang. Profesi tersebut disusun oleh keluarga yang melaksanakan pesta adat Mappadendang, tapi jika pemerintah atau kelompok tani yang melaksanakan pesta adat tersebut maka dibuatlah sebuah struktur panitia.proses pelaksanaan pesta adat Mappadendang diakhiri dengan makan bette bersama dengan seluruh masyarakat yang hadir dalam pesta adat tersebut. Namun ada prosesi penting dalam acara makan bersama tersebut yaitu mengirim doa kepada tuhan atas berkah musim panen yang telah diberikan kepada mereka. Hal ini juga senada dengan yang diungkapkan masher bahwa dalam prose pelaksanaan pesta adat Mappadendang memiliki susunan acara yang diakhiri dengan makan bersama.

Dapat diketahui bahwa pesta adat Mappadendang memiliki peran yang cukup penting dalam kehidupan bermasyarakat bagi warga setempat. Karena dengan pesta adat tersebut mereka bisa bersilaturahmi dengan masyarakat lainnya lewat sebuah pertunjukkan sambil menikmati hidangan yang telah disediakan. Dari beberapa penjelasan informan tersebut dapat pula dipahami bahwa pesta adat Mappadendang juga memiliki arti penting dalam kehidupannya, karena dengan tetap 
melestarikan pesta adat tersebut berarti mereka juga telah menjaga warisan dan kepercayaan dari nenek moyang atau leluhur mereka.

\section{2) Pakaian dalam pelaksanaan Ritual Adat} Mappadendang di Desa Pationgi Kecamatan Patimpeng Kabupaten Bone

Pakaian sebagai bagian dari kebutuhan setiap orang saat ini telah menjadi sebuah daya tarik sehingga sangat menunjang penampilan seseorang. Didalam kehidupan sehari- hari, Pakaian yang menjadi kebutuhan pokok setiap orang, hal ini dapat dilihat dari kebiasaan setiap orang yang menggunakan pakaian khusus dalam berkegiatan atau mengikuti sebuah acara khusus.

Pakaian memiliki makna tersendiri bagi setiap orang, seperti halnya dalam kehidupan masyarakat bugis di Kabupaten Bone ketika mengenakan pakaian dalam kehidupan sehari- hari. Mereka mengenakan pakaian yang dianggap tidak menyalahi adat istiadat atau aturan yang berlaku dalam masyarakat tersebut, contohnya berpakaian yang sopan dan bersih salah satu contoh kecil dalam adat. Baju adat tersebut memiliki makna sebagai keindahan, bahwa suku bugis selalu menjaga keindahan dan baju adat tersebut sebagai symbol keindahannya.

"iyye engka ada seragangnya baju adat, kalo indo' padendang'e pake baju bodo, kalo ambo padendang'e pake jas tutu' bisa songko passapu. Itu baju bodo ndi' supaya cantik eh menjaga ade' jadi harus ada baju bodo dipake supaya cantik dan gagah- gagah pemain padendang'e.

Hal ini dipertegas oleh Latalibe yang merupakan salah satu pemain dalam pesta adat Mappadendang yang menyatakan bahwa pemain dalam pesta adat Mappadendang yang menyatakan bahwa pemain dalam pesta adat Mappadendang mengenakan seragam, pemain laki- laki dan perempuan mengenakan baju khusus yaitu baju adat suku bugis.

"iya biasanya itu baju- baju adat memang, kalau laki- lakinya kain biasanya dililitkan dikepala sama penutup kepala sering disebut passapu', sedangkan bajunya baju jasa tertutup warna hitam terus sarung, sedangkan perempuannya baju bodo".

Dari apa yang dijelaskan oleh beberapa narasumber diatas dapat dilihat bahwa dalam pelaksanaan pesta adat Mappadendang, pemain tersebut mengenakan pakaian seragam yaitu baju adat Suku bugis. Hal ini dikarenakan agar pemain dalam pesta adat Mappadendang terlihat menarik dan ketika masyarakat di Desa Pationgi melaksanakan sebuah pesta adat maka harus mengenakan baju adat Suku bugis.

\section{Makna Ritual Pesta Adat Mappadendang Bagi Masyarakat Desa Pationgi Kecamatan Patimpeng Kabupaten Bone}

Kehidupan manusia berjalan mengikuti alur waktu, disetiap proses perjalananya banyak hal yang terjadi dalam kehidupan manusia. Tindakan dan tingkah laku manusia terjadi bukan tanpa sebab melainkan sebuah proses interaksi manusia itu sendiri, tindakan tersebut memiliki makna tersendiri yang mungkin saja akan menghasilkan pemahaman yang berbeda dari setiap individu manusia. Salah satu contoh yang dapat kita lihat yaitu sebuah tradisi dan adat istiadat itu terus dipertahankan sampai saat ini dan memiliki mkna bagi setiap manusia yang menyakini.

Bagi masyarakat pedesaaan yang menggantungkan kehidupannya pada pertanian, memiliki kehidupan yang sederhana, tenang dan memiliki tradisi serta adat istiadat yang dipertahankan hingga saat ini adalah sebuah kewajiban. Tidak dipungkiri mungkin hal inilah yang membuat kebersamaan dan kekeluargaan 
masyarakat yang hidup dan menetap di pedesaan tetap terjaga dengan baik. Hal itu juga dapat kita lihat ketika masyarakat pedesaan menunjukkan rasa syukur mereka terhadap tuhan apabila musim panen padi telah tiba. Rasa syukur tersebut mereka gambarkan dalam sebuah pesta adat yang disebut pesta adat Mappadendang

Mappadendang merupakan upacara syukuran panen padi dan merupakan adat masyarakat bugis sejak dahulu kala. Dilaksanakan setelah panen raya biasanya memasuki musim kemarau pada malam hari. Tardisi ini sudah berjalan turuntemurun bagi masyarakat yang bergantung dari hasil usaha bertani umumnya mengenal pesta adat ini. Mulai dari turun kesawah, membajak, sampai tiba waktunya panen raya. Banyak masyarakat yang berpendapat bahwa pesta adat Mappadendang memiliki makna yang sangat dalam bagi petani di pedesaan, pesta adat tersebut menggambarkan kehidupan petani dipedesaan yang sangat bersahaja dan mengingatkan kita kepada sebuah penghormatan terhadap tuhan, tanah dan padi yang memberikan kehidupan bagi manusia,. Menurut Nurbaya pesta adat Mappadendang sesuatu yang sangat bermakna bagi masyarakat Desa Pationgi karena bisa berkumpul dan menjalin silaturahmi.

"kan itu orang sukurang, jadi dipanggil orang making bette' sebagai rasa sukur, kebersamaan, kekeluargaan, karna waktu ma' tanangki ase nabantuiki juga. Kalo datangmi orang menonto padendang'e makan meki bette' sama- sama, kalo sediki'ji bette' ta ji juga yang penting makanki samasama. Kah tidak boleh itu tidak dikasi makan orang, anu bede ndi' semanga'na itu padi beras kalo banya, orang makangi". Nah begini ndi' kalo maumi mulai acarata mappadendang'e suara alu itu seperti lonceng tanda pesta'e mulai, warga itu kampong sebelah
mulaimi datang. (nurbaya, 2018)

Dari apa yang dijelaskan oleh nurbaya sangat jelas bahwa pesta adat Mappadendang merupakan sesuatu yang menyenangkan bagi dirinya dan masyarakat di Desa Pationgi karena mereka dapat berkumpul dan menjalin silahturahmi dengan masyarakat Desa Lainnya, tak hanya itu penjelasannya dapat dilihat bahwa pesta adat Mappadendang memiliki makna yaitu rasa syukur atas berkah dan limpahan rezeki berupa padi yang telah mereka panen. Selain itu, seperti apa yang telah diungkapkan oleh nurbaya diatas makna Mappadendang juga dapat kita ibaratkan sebuah doa kepada tuhan agar kiranya panen yang akan datang bisa lebih baik lagi dan kembali dapat berkumpul dalam pesta adat Mappadendang. Lebih menarik lagi bahwa suara alu aatu lesung memiliki makna sebagai petanda pesta adat Mappadendang juga diungkapkan oleh pendre bahwa ketika musim panen padi berhasil maka pesta adat Mappadendang harus dilaksanakan.

'itumi ndi' kalo Mappadendang'e sudah turun- temurun dari nenek moyang ta dulu jadi itumi haruski dilakukang, kalo baguski hasil panen berarti Mappadendangki ndi" oh, itu baju bodo ndi' sama hiburang'e ada artina juga ndi' itu maksudnya baju bodo supaya dilihat cantik eh anu ndi' kita juga orang bugis setiap ada acara selalu pake baju bodo menjaga ade' ndi'.

Dari apa yang diungkapkan oleh latalibe sangat jelas bahwa pesta adat Mappadendang bagi masyarakat Desa Pationgi selain bermakna rasa syukur terhadap tuhan atas berkah dan limpahan rezeki berupa padi yang telah mereka panen, juga memiliki makna menghargai dan menjaga warisan dari leluhur atau nenek moyang mereka berupa tradisi dan adat- istiadat yang menjadi pedoman dalam 
hidup mereka dan hiburan dalam prosesi pesta adat tersebut dimaknai sebagai pelekat dan penjaga keharmonisan serta memberikan hiburan bagi masyarakat setelah lelah menghabiskan waktunya berladang. Bagi masyarakat Desa Pationgi pesta adat Mappadendang mempunyai makna menghargai dan menjaga warisan dari leleuhur atau nenek moyang mereka berupa tradisi dan adat- istiadat yang menjadi pedoman dalm hidup mereka.

Dari apa yang dijelaskan oleh beberapa narasumber diatas bahwa pesta adat Mappadendang bagi masyarakat Desa Pationgi dimaknai sebagai ungkapan rasa syukur kepada tuhan atas berkah dan limpahan rezeki berupa padi yang telah mereka panen serta sebagai penghargaan terhadap leluhur atau nenek moyang mereka dengan cara mejaga warisan tradisi dan adat istiadat yang menjadi pedoman dalm hidup mereka. Bagi masyarakat Desa Pationgi, pesta adat Mappadendang memberikan kebahagiaan tersendiri karena dapat berkumpul dan berbagai kepada sesame masyarakat di Desa Pationgi.

Dari penjelasan diatas dapat diketahui bahwa pesta adat Mappadendang memiliki arti penting bagi masyarakat tersebut, pesta adat Mappadendang berperan sebagai simbol bahwa masyrakat senantiasa bersyukur atas apa yang telah tuhan berikan kepada mereka. Arti penting tersebut sebagai pernada dan pengingat bahwa manusia selalu bersyukur.

\section{Nilai- Nilai yang Terkandung di dalam Ritual Pesta Adat Mappadendang}

Pesta adat Mappadendang tidak hanya sebatas pesta adat biasa, bahkan hampir diseluruh daerah dan suku di Sulawesi Selatan memiliki pesta adatnya masingmasing, tak hanya itu pesta adat tersebut memiliki pengaruh penting dalam kehidupannya sehari- hari. Pesta Adat Mappadendang bagi masyarakat suku bugis di Kabupaten Bone memiliki tempat tersendiri dalam kehidupannya, ini dikarenakan banyak nilai- nilai yang terkandung di dalam pesta adat tersebut
Nilai- nilai tersebut terus bertahan dan menjadi prekat hubungan sosial didalam masyarakat yang saat in isemakin tergerus oleh perkembangan zaman. Ketika kita meperhatikan dan mengamati lebih mendalam lagi mengenai kehidupan masyarakat pedesaanyang kental akan nilainilai kebersamaan dan kekeluargaan, secara tidak langsung kita juga akan menyentuh tradisi dan adat istiadat masyarakat di pedesaan tersebut, hal ini karenakan tradisi dan adat istiadat tersebut mengandung nilainilai yang menjadi perekat hubungan sosial diantara mereka. Tradisi dan adat- istiadat tersebut dapat berupa sebuah pertunjukkan atau ritual- ritual seperti pesta adat Mappadendang hal ini juga diungkapkan oleh hj. Andi Nirma yang merupakan tokoh masyarakat di kecamatan Patimpeng bahwa pesta adat Mappadendang. Memiliki nilai- nilai yang mampu menghidupkan semangat kebersamaan dan kekeluargaan didalam masyarakat.

"iya ketika Mapadendang itu dilaksanakan saya melihat masyarakat itu senang sekali, mungkin mereka terhibur karena biasa bertemu dengan tetangga- tetangga Desa, pokoknya banyak warga yang datang, yang paling bagus itu kalau kita makan bersama." (nirma, 2018)

Mappadendang merupakan sesuatu yang sangat menarik dan menyenagkan bagi masyarakat, hal ini dapat dilihat dari penjelasan narasumber bahwa ketika pesta adat Mappadendang dilaksanakan masyarakat terlihat sangat senang dan beramai- ramai berdatangan ke pesta adat tersebut. Lebih menarik lagi adalah bunyi alu memiliki makna sebagai pertanda bahwa pesta adat tersebut telah dimulai. Hal ini senada dengan yang diungkapkan oleh Muh. Tola yang juga merupakan tokoh masyarakat dikecamatan Patimpeng.

"kalo daerah sekitar sini di wilayah di
wilayahku, warga itu sering datang
bertanya kapan lagi diadakan


mappadendang. Saya juga suka sekali kalo ada kelompok tani melapor mau adakan. Karena ramai lagi kampung, itu kan mappadendang, karena ramai lagi kampong, itu kan mappadendang ada juga pertunjukanya jadi muda terhibur, kita juga orang tua suka karena merasa teringat sama waktu dulu sekali itu nenekkalo adakan mappadendang.

Nilai- nilai hiburan tersebut di gambarkan dalam sebuah irama musik alu yang ditimbulkan pada palungeng dan dipadukan dengan alat musik yang digunakan pada saat pelaksanaan pesta adat, selain itu nilai- nilai hiburan dalam pesta adat mappadendang tersebut dapat dilihat ketika pemain menari- nari dan melakukan astraksi- astraksi yang membuat penonton terhibur. Namun, menurut junnah yang merupakan tokoh masyarakat dikecamatan Patimpeng dan juga berprofesi sebagai pegawai dikantor Desa Pationgi bahwa selain nilai- nilai hiburan, didalam pesta adat mappadendang juga tersebut nilai- nilai spiritual. Hal ini dapat dilihat ketika masyarakat mengemukakan alasannya melaksanakan pesta adat mappadendang yaitu mengungkapkan rasa syukur kepada tuhan atas berkah dan limpahan rezeki berupa padi yang telah mereka panen.

anu nak , warga adakan itu mappadendang'e karena mau berterima kasih, bersyukur dia karena sukses panen rayanya. Semoga tuhan kasi lagi panen raya tahun depan kan murah sekarang harga gabah, itu bulog murah sekali kasi harga, harganya itu sekarang tadi rapat dikantor desa sama bulog cuman tiga ribu lima ratus rupiah, jadi kalo sukses panen raya biar murah tapi kalau banyak padi bisa jeki hidup ndi', jadi semuanya dari tuhan”.
Adanya sebuah hubungan yang kuat antara manusia dan tuhan dalam kehidupan masyarakat sehari hari,hal ini digambarkan dalam sebuah pesta adat mappadendang dengan nilai nilai spiritual didalamnya yang menjadi penghubung dan perekat hubungan antara manusia dan tuhanya.selain nilai nilai spiritual yang terkandung dalam pesta adat mappadendang, terdapat nilai nilai lainya yang menjadi salah satu faktor terjaganya hubungan yang harmonis dalam kehidupan sehari hari masyarakat desa pationgi.nilai nilai tersebut adalah nilai kebersamaan dan kekeluargaan yang dapat jelas kita lihat dalam proses pelaksanaan pesta adat mappadendang,hal ini diungkapkan oleh Nurbaya dalam salah satu kesempatan wawancara dikediamanya yaitu desa pationgi.

"itu warga datang sendiriji, dari kampong jauh juga,itu ehh warga baku panggil panggilki bilangi mau pergi makang bette' kah bunyi padendang'e. kan itu sukurang jadi panggilmi orang makang bette'.sebagai rasa kebersamaan kekeluargaanta karna waktu tanamki padi nabantuiki juga ndi',kalo datangmi orang eh sudahmi dibaca di makanmi sama sama kalo sediki’ji bette'ta’ji juga yang penting makangki sama sama,atau sokko'di kasi makang, ka tidak boleh itu tidak di kasi makang orang,anu bede semangatna itu beras kalo banyak orang makangi”.

Dari apa yang dijelaskan nurbaya diatas dapat dilihat bahwa nilai nilai kebersamaan dan kekeluargaan memang jelas terkandung dalam pesta adat mappadendang, ketika masyarakat beramai ramai datang ke pesta adat mappadendang dan makan bersama. Tak hanya itu,nilai nilai kebersamaan dan kekeluargaan masyarakat tersebut terus terjaga mulai dari 
proses menanam padi hingga musim panen dan pesta adat mappadendang kembali dilaksanakan.

Nilai- nilai yang terkandung didalam pesta mappadendang tersebut memberi pesan moral yang baik didalam agama maupun adat- istiadat bahwa sesuatu hal yang paling berharga dalam hidup ini adalah menjaga hubungan dengan tuhan dan menjaga hubungan dengan sesame manusia. Pesta moral ini tergambarkan dengan jelas pesta dalam pesta mappadendang ketika memahami dengan baik nilai-nilai spiritual, nilai-nilai kebersamaan dan kekeluargaan, serta nilainilai hiburan.

Dalam penjelasan ini pula dapat dipahami bahwa arti penting pesta adat tersebut dapat dilihat dalam setiap nilai-nilai yang terkandung didalamnya. Nilai spiritual,kebersamaan,dan kekeluargaan, serta hiburan merupakan sesuatu yang sangat penting bagi mereka karena hal inilah yang perlu dijaga agar keselarasan hidup manusia,alam,dan tuhanya dapat terjaga.

\section{E. Kesimpulan}

Didalam proses pelaksanaannya pesta adat Mappadendang memiliki waktu pelaksanaan yang khusus dan telah ditentukan sejak dahulu hingga sampai saat ini. Waktu pelaksanaanya harus mengikuti tradisi yaitu setelah musim panen dan memasuki musim kemarau di malam hari. Alasan mengapa pesta adat Mappadendang dilaksanakan di malam hari adalah mengikuti tradisi nenek moyang serta tidak adanya aktifitas bertani di malam hari. Selain waktu yang telah ditentukan, pakaian pemain dalam pesta tersebut juga ditentukan yaitu baju adat suku bugis, alasannya sederhana yaitu ketika masyarakat mengadakan pesta adat maka harus pula mengenakan pakaian adat. Selanjutnya tata cara pelaksanaan pesta adat Mappadendang adalah pemain perempuan berjumlah empat orang sedangkan laki- laki berjumlah tiga orang, memiliki tugasnya masing- masing yaitu memadukan irama tumbukan alu pada palungeng dan alat musik yang digunakan serta memadukan tarian- tarian atau atraksi- atraksi yang dipertontonkan. Selain menumbukkan alu pada palungeng, pemain harus menumbuk padi sampai selesai dan berakhirlah pesta adat Mappadendang yang ditutup dengan makan malam bersama seluruh masyarakat yang hadir.

Adapun makna pesta adat Mappadendang tersebut bagi masyarakat Desa Pationgi adalah rasa syukur terhadap tuhan atas berkah dan limpahan rezeki berupa padi yang telah mereka panen. Selain itu bagi masyarakat Desa Pationgi pesta adat tersebut adalah doa kepada tuhan agar panen yang akan datang bisa lebih baik lagi dan dapat berkumpul kembali kedalam pesta adat Mappadendang.

Di dalam proses pelaksanaan pesta adat Mappadendang ada nilai- nilai yang tekandung dan terus dijaga oleh masyarakat Desa Pationgi, nilai- nilai tersebut berupa nilai hiburan yang menjadi perekat hubungan sosial pada masyarakat setempat, selanjutnya adalah nilai spiritual yang juga menjadi perekat dan penghubung manusia dan tuhannya. Dan yang terakhir adalah nilai- nilai kebersamaan dan kekeluargaan. Nilai- nilai yang terkandung didalam pesta adat Mappadendang tersebut memberikan pesan moral yan baik didalam agama maupun adat istiadat bahwa sesuatu hal yang paling berharga dalam hidup ini adalah menjaga hubungan dengan tuhan dan menjaga hubungan sesama manusia.

\section{DAFTAR PUSTAKA}

Abbas, 2018. Wawancara [Interview] (Mei 2018).

Ahmadin., 2013. Metode Penelitian Sosial. Makassar: Rayhan Intermedia. 
Hamid., M. S. M. d. A. R., 2008. Pengantar Ilmu Sejarah.. Makassar: Rayhan Intermedia.

Latalibe, 2018. Wawancara [Interview] (Mei 2018).

Mashar, 2018. Wawancara [Interview] (Mei 2018).

nirma, H. A., 2018. Wawancara [Interview] (Mei 2018).

Nonci, 2006. konsep- konsep budaya masyarakat.. s.l.:CV AKSARA.

riyani, N., 2010. Tradisi Mappadendang dalam Masyarakat Petani di Kabupaten Sidenreng Rappang (1981-2008), . In: Skripsi. s.l.:Universitas Negeri Makassar..

Sjamsuddin., H., 2012. Metodologi Sejarah, (Yogyakarta: Ombak, 2012), hlm. 103.. Yogyakarta: Ombak.

Surjomiharjo, T. A. d. A. R., 1985. ilmu Sejarah dan Historiografi. Jakarta: Gramedia Pustaka Utama.

Sztompa, P., 2008. Sosiologi perubahan sosial. Jakarta: Preinada. 